\title{
Office types and workers' cognitive vs affective evaluations from a noise perspective
}

\author{
Tobias Otterbring \\ Department of Management, School of Business and Law, University of Agder, \\ Kristiansand, Norway \\ Christina Bodin Danielsson \\ School of Architecture and the Built Environment, KTH Royal Institute of Technology, \\ Stockholm, Sweden, and \\ Jörg Pareigis \\ Karlstad Business School, CTF, Service Research Center, Karlstad University, \\ Karlstad, Sweden
}

Office types, noise, and well-being

Received 27 September 2019 Revised 19 March 2020 18 July 2020

\begin{abstract}
Purpose - This study aims to examine the links between office types (cellular, shared-room, small and medium-sized open-plan) and employees' subjective well-being regarding cognitive and affective evaluations and the role perceived noise levels at work has on the aforementioned associations.

Design/methodology/approach - A survey with measures of office types, perceived noise levels at work and the investigated facets of subjective well-being (cognitive vs affective) was distributed to employees working as real estate agents in Sweden. In total, 271 useable surveys were returned and were analyzed using analyses of variance (ANOVAs) and a regression-based model mirroring a test of moderated mediation.

Findings - A significant difference was found between office types on the well-being dimension related to cognitive, but not affective, evaluations. Employees working in cellular and shared-room offices reported significantly higher ratings on this dimension than employees working in open-plan offices, and employees in medium-sized open-plan offices reported significantly lower cognitive evaluation scores than employees working in all other office types. This pattern of results was mediated by perceived noise levels at work, with employees in open-plan (vs cellular and shared-room) offices reporting less satisfactory noise perceptions and, in turn, lower well-being scores, especially regarding the cognitive (vs affective) dimension.

Originality/value - This is one of the first studies to compare the relative impact of office types on both cognitive and affective well-being dimensions while simultaneously testing and providing empirical support for the presumed process explaining the link between such aspects.
\end{abstract}

Keywords Office type, Cellular office, Shared-room office, Open-plan office, Noise, Subjective well-being, Cognitive evaluation, Affective evaluation, Positive activation, Negative deactivation

Paper type Research paper

\section{Introduction}

The office environment influences people both individually and at the group level, with potential impact on organizational well-being, productivity and work success, as well as workplace conflicts, sickness absence and job (dis-)satisfaction (Bernstein and Turban, 2018; Bodin Danielsson et al., 2015; Goldman, 1994; Pejtersen et al., 2011; Otterbring et al., 2018a). Indeed, research indicates that the choice of office type, defined by its setup of architectural

(C) Tobias Otterbring, Christina Bodin Danielsson and Jörg Pareigis. Published by Emerald Publishing Limited. This article is published under the Creative Commons Attribution (CC BY 4.0) licence. Anyone may reproduce, distribute, translate and create derivative works of this article (for both commercial and non-commercial purposes), subject to full attribution to the original publication and authors. The full terms of this licence may be seen at http://creativecommons.org/licences/by/4.0/legalcode

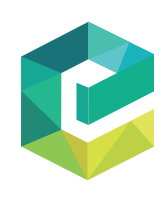

Journal of Managerial Psychology Vol. 36 No. 4,2021 Emerald Publishing Limite 0268-3946 DOI 10.1108/JMP-09-2019-0534 
JMP

36,4

and functional features, could play a key role in predicting a set of crucial outcomes for companies and organizations. For example, significant differences have been found between employees working in different office types regarding health-related aspects (Bodin Danielsson and Bodin, 2008), with such findings often explained by differential levels of exposure to "environmental stressors" in different office types (Bell et al., 2001; Carlopio and Gardner, 1992).

One important environmental stressor is noise, defined as unwanted and disturbing sounds, including conversations by colleagues and sounds from telephones, office equipment and people walking by (Sundstrom, 1986). In fact, noise is the most prevalent annoyance source in offices (Becker, 1981) and, as such, fairly well researched. For instance, studies have shown that noise from open-plan offices and similar environments has a negative impact on cognitive performance and restoration (Jahncke et al., 2011) and also on writing abilities (Keus van de Poll and Sörqvist, 2016) and perseverance (Evans and Johnson, 2000). Furthermore, noise has been shown to exert a negative influence on mental workload (Smith-Jackson and Klein, 2009). However, although research on the cognitive manifestations following real or perceived noise exposure is relatively clear, conclusions on how affective responses relate to noise perceptions are difficult to draw with certainty.

The main objective of the present study was to compare the relative impact of office types on both cognitive and affective well-being dimensions while simultaneously testing the process (i.e. perceived noise levels at work) assumed to explain the link between office types and such well-being-related aspects. From a practical point of view, organizations spend billions of dollars worldwide to implement the concept of open-plan offices, despite several studies demonstrating detrimental effects of such office types on a variety of organizational outcomes. Nevertheless, there is a general lack of understanding pertaining to the processes and circumstances explaining such results. Importantly, beyond the "gap spotting" involved in addressing a scarcely studied research topic (Alvesson and Sandberg, 2011; Ashkanasy, 2011), scholars have called for more research on how employees respond affectively and cognitively in different office configurations and which mediating mechanisms that may explain such responses (Ashkanasy et al., 2014). Therefore, this study addresses the call for theoretically relevant research aimed at disentangling the particular psychological processes and boundary conditions explaining when and why different office types are associated with differential well-being responses. Addressing this aim may eventually enable a more nuanced theoretical account of the interplay between our studied constructs (i.e. office types, perceived noise levels at work and affective and cognitive well-being responses). However, we willingly acknowledge that our paper primarily has relevance for managerial and business practice as its ultimate goal (cf. Birkinshaw et al., 2014; Cialdini, 2009; Hambrick, 2007; Otterbring et al., 2020; Rynes et al., 2001; Suddaby, 2014).

\section{Theory and hypotheses}

According to the cognitive activation theory of stress (CATS; Ursin and Eriksen, 2004), exposure to negative environmental stressors (e.g. the increased noise levels typically found in open offices) may induce cognitive reactions related to stress, disturbance and annoyance. These reactions may subsequently lead to various negative outcomes, including less favorable cognitive evaluations and impaired performance on cognitively demanding tasks (Block and Stokes, 1989; Hoendervanger et al., 2019; Seddigh et al., 2014; Sundstrom et al., 1980). Additionally, such negative outcomes may generate spillover effects on other aspects, beyond cognitive operations (e.g. affective responses). This line of reasoning is consistent with cognitive appraisal theories, which argue that emotion-eliciting situations tend to be cognitively processed in a way that modifies their emotional impact before this impact has fully occurred (Gross and John, 2003; Brockman et al., 2017). Thus, a change in the content of 
cognitions can be used to regulate emotions in a way resembling this cognitive content (Brockman et al., 2017).

Cognitive appraisal theories (Folkman et al., $1986 \mathrm{a}$, b) postulate that two processes indirectly influence the assumed dynamic, reciprocal and bidirectional relationship between a person and a stressful environment: cognitive appraisal and coping. Cognitive appraisal is when the person evaluates whether a certain encounter with the environment may have wellbeing-related consequences and, if so, in which way (Folkman et al., 1986a). Such an account assumes that emotion is always a response to some form of cognitive activity or, stated differently, that emotion cannot occur without cognition (Lazarus, 1991). In primary appraisal, the person evaluates the potential harm or benefit that exists in the environment. Secondary appraisal reflects an evaluation of what, if anything, the person can do to prevent harm or boost the prospects for benefit (Folkman et al., 1986b). A part of the secondary appraisal lies an evaluation of various coping options, with coping defined as "efforts to manage [...] the internal and external demands of the person-environment transaction that is appraised as taxing or exceeding the person's resources" (Folkman et al., 1986a, p. 572). Coping has two primary purposes: regulating emotion and addressing the personenvironment relationship that is causing distress (Folkman et al., 1986b). In sum, appraisal theories of psychological stress and coping treat affective reactions as arising in response to events that an individual (cognitively) interprets as potentially having well-being-related consequences, with these consequences and their perceived importance being appraised in some way (Folkman et al., 1986a, b; Lazarus, 1991; see also Frijda, 1987, 1988).

The literature delineated above suggests that open office spaces may not only exert a negative impact on employees' cognitive evaluations, hereafter viewed as employees' beliefs and perceptions regarding the functional aspects of their work environment. Rather, these office spaces may also create a negative spillover effect in which employees' affective evaluations, defined as their feelings toward and attachment to the work environment, become less favorable (Ashkanasy et al., 2014; Evans and Johnson, 2000; Jahncke et al., 2011; Roberts et al., 2019; Seddigh et al., 2014). Thus, different office types may be associated with changes in employees' responses in two different evaluations domains (i.e. cognitive and affective evaluations).

However, while appraisal theories perceive affective evaluations as arising after a change in the cognitive content has occurred, other theoretical streams do not take such a chain of events for granted. A contrasting view to the idea that cognitive processes always act as antecedents of affective evaluations and subsequent behavioral responses is a perspective proposed by Zajonc (1980). His "preferences need no inferences" conceptualization postulates that affective reactions may very well precede, and take place independent of, cognitive operations. Indeed, an increasing number of scholars, including several famous dual-process theorists, conceptualize the mental processes involved in evaluative judgments as two rather independent systems: one characterized by automatic (affective) aspects and one characterized by controlled (cognitive) components (e.g. Hofmann et al., 2009; Kahneman, 2011; Metcalfe and Mischel, 1999; Petty and Cacioppo, 1986; Strack and Deutsch, 2004). As such, preferences, attitudes, and, ultimately, behavior may sometimes be formed or changed mainly as a function of the particular affective reactions evoked, with little or no impact of cognition (Lerner et al., 2015).

Yet, regardless of whether affective and cognitive evaluations are conceptualized as distinct or inter-related constructs, the link between office type and such evaluative judgments should arguably be stronger for cognitive evaluations while still exerting some impact on affective evaluations (Ashkanasy et al., 2014; Kaarela-Tuomaala et al., 2009; Oldham and Brass, 1979). For example, beyond cognitive constructs, Bodin Danielsson and Bodin (2008) found differences in emotional health as a function of office types, with openplan (vs cellular) offices yielding inferior results on affect-related measures, such as calmness

Office types, noise, and well-being 
JMP

36,4

418

and harmony. These findings were attributed to variations in the architectural and functional features of the studied office types (e.g. greater interference from conversations and background noise in open-plan offices and increased difficulties for employees to seek privacy in such open office spaces). Furthermore, some scholars have found a link between employees' distraction and disturbance levels due to noise and their overall evaluations of their office environments (Nemecek and Grandjean, 1973), with others having documented differences in these factors as a function of office types (Bodin Danielsson and Bodin, 2009; Sundstrom et al., 1994). Based on these findings, and given the lack of explicit knowledge as to whether the impact of office types on employees' cognitive and affective well-being evaluations could be indirect through the mediating mechanism of perceived noise, the present study investigated the accuracy of two primary predictions (see Figure 1 for the corresponding conceptual model). To understand these predictions, we firstly describe the characterizing architectural and functional features of our examined office types (i.e. cellular office, shared-room office, small open-plan office and medium-sized open-plan office), as defined by Bodin Danielsson and colleagues (Bodin Danielsson and Bodin, 2008; Bodin Danielsson et al., 2015). Architectural features include physical aspects, such as the spatial organization of the office, whereas functional features relate to the actual work taking place at the office and how this work is structured, as determined by functional needs and technical solutions (Bodin Danielsson et al., 2015).

Cellular offices are typically situated in long corridors, with multiple small offices connected to each other, most facilities being found within the room and the employees having a single room office with a window, where they tend to work independently on tasks requiring concentration. Shared-room offices are offices where 2-3 colleagues, who usually have similar work tasks, share a single room, often with workstations freely arranged in the room and sometimes separated by screens, cubicles or other bounded elements that provide visual closure and privacy. In contrast to cellular offices, most facilities are found outside shared-room offices and the employees do not have an individual window. Small open-plan offices and medium-sized open-plan offices are shared rooms where 4-9 (small) or 10-24 employees (medium-sized) have workstations, frequently divided into groups, with screens and other artifacts (e.g. plants) between the workstations to reduce noise and provide some privacy. Employees mostly work independently on routinized tasks and low levels of interaction, with facilities sometimes placed at the individual workstations. Such open office spaces mainly serve to be flexible to organizational changes and tackle such changes without the need for physical reconfigurations. Based on these definitions and the literature delineated above, we propose the following two key hypotheses:

H1. There is a negative association between office type (from cellular, through sharedroom, to small and medium-sized open-plan offices) and employees' well-being evaluations, with employees in small and medium-sized open-plan offices reporting less positive evaluations than employees in cellular and shared-room offices.

Figure 1.

Perceived noise as the mediator for the link between office type and participants' wellbeing evaluations

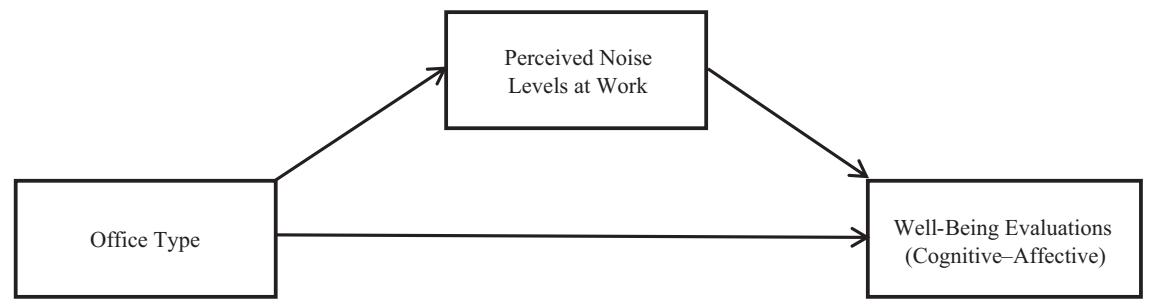


However, this association is moderated by evaluation domain and is stronger for cognitive (vs affective) well-being evaluations.

H2. The link between office type and employees' well-being evaluations is mediated by perceived noise levels at work. Employees in small and medium-sized open-plan offices report more negative well-being evaluations than employees in cellular and shared-room offices due to inferior noise perceptions, especially regarding cognitive (vs affective) well-being evaluations.
Office types, noise, and well-being

\section{Method}

The data were collected in connection to another project, which examined the link between office type and job satisfaction and the mediating roles of subjective well-being and employees' cooperation and collaboration with colleagues (Otterbring et al., 2018a). An online survey was distributed to 1,500 employees working as real estate agents in several distinct offices throughout Sweden. In total, 305 employees replied to the survey, giving a response rate of approximately $20 \%$. Because 34 employees did not state how many individuals, if any, they shared an office with, 271 useable surveys were included in the analyses (39\% male; $M_{\text {age }}=40$ years), with missing values replaced by group means. Participants replied to a set of items related to office type, perceived noise levels at work, affective and cognitive components linked to well-being and other study-specific variables. Initially, participants indicated if they shared office with somebody and, if so, with how many. Office type groups were created based on the number of employees with whom the participants shared their office using an established categorization method from Bodin Danielsson and Bodin (2008). To this end, participants were categorized as working in cellular offices if they indicated that they worked alone in an office, whereas they were classified as working in shared-room offices in case they stated that they shared an office with one or two colleagues. Similarly, participants who reported that they shared an office with 3-9 colleagues were operationalized as belonging to small open offices, while all the remaining participants who indicated that they worked in an office with 10-20 colleagues were treated as working in medium-sized open offices.

Having indicated with how many colleagues, if any, participants shared an office, they then stated how they perceived the noise levels at their office on a single-item seven-point scale $(1=$ negative; $7=$ positive). For doubly concrete constructs (i.e. constructs that are clear and easily understood), single-item scales are at least as valid as multi-item scales in predicting organizational outcomes and other aspects of relevance for managerial decisionmaking (Abdel-Khalek, 2006; Bergkvist and Rossiter, 2007; Gardner et al., 1998; Nagy, 2002; Otterbring, 2020; Wanous et al., 1997). Following the perceived noise measure, participants replied to items from the Satisfaction with Travel Scale (STS; Ettema et al., 2011), which measures three separate dimensions of subjective well-being: cognitive evaluation, positive activation/negative deactivation and negative activation/positive deactivation. The STS has been used in a wide variety of contexts related to aspects such as employee productivity, cognitive performance, loyalty intentions and job satisfaction (e.g. Friman et al., 2020; Ma and Ye, 2019; Otterbring et al., 2018a; Westman et al., 2017). This scale was selected as it includes both cognitive and affective well-being evaluations, consistent with the notion that workrelated well-being comprises the evaluations employees make about their working life experiences, which involve cognitive as well as affective aspects (Bakker and Oerlemans, 2011). The STS items were slightly rephrased to fit the context and were rated on nine-point scales ranging from -4 , through 0 to 4 . To capture the cognitive well-being component, participants indicated their responses on three items meant to represent how they had thought about their office during the last week (my office is bad-good, the standard of the 
JMP

36,4

work environment at my office is low-high, the layout of my office is the worst I can think ofthe best I can think of). These items were then averaged into a composite index of cognitive evaluations $(\alpha=0.84)$ [1]. Similarly, to capture the affective well-being component, the three items pertaining to the positive activation/negative deactivation dimension (tired-alert, bored-enthusiastic and fed up-engaged) were averaged to create an index variable of affective evaluations $(\alpha=0.80$ ), thus reflecting how participants had felt at their office during the last week. Due to a technical error, one item was missing from the negative activation/ positive deactivation scale, and because the reliability of the two remaining items (time pressed-relaxed; stressed-calm; $\alpha=0.67$ ) was below the generally accepted benchmark for a reliable scale (Clark and Watson, 1995; Nunnally, 1978), these components were discarded from the main analyses [2].

\section{Results}

\section{Descriptive details}

In total, 76 participants $(28.0 \%)$ indicated that they worked alone in an office (i.e. cellular office). Among the remaining participants, $45(16.6 \%)$ stated that they shared an office with one or two colleagues (i.e. shared-room office), $113(41.7 \%)$ reported that they shared an office with 3-9 colleagues (i.e. small open office) and $37(13.7 \%)$ indicated that they worked in an office with 10-20 colleagues (i.e. medium-sized open office).

One-sampled $t$-tests revealed that the grand means were significantly above the scale midpoint of 0 for both the cognitive evaluations index $(M=1.75, \mathrm{SD}=1.74, t(270)=16.55$, $p<0.001)$ and the affective evaluations index $(M=1.56, \mathrm{SD}=1.48, t(270)=17.37, p<0.001)$, indicating that participants generally gave positive well-being ratings in both evaluation domains. However, for perceived noise levels at work, participants' grand mean ratings did not differ significantly from the scale midpoint of $4(M=3.96, \mathrm{SD}=1.46, t(270)=-0.43$, $p=0.666$ ), suggesting that they were relatively indifferent or neutral toward this factor at the aggregate level (i.e. without considering the impact of office type on these ratings).

\section{Evaluation domain moderates the impact of office type on well-being evaluations}

To examine whether office type and evaluation domain interacted to influence participants' ratings of well-being-related aspects (H1), a 4 (office type: cellular office, shared-room office, small open office, medium-sized open office) $\times 2$ (evaluation domain: cognitive, affective) mixed ANOVA was conducted. Office type was the between-subjects factor, and the evaluation domain served as the within-subjects factor. This analysis found no main effect of evaluation domain $\left(F(1,267)=2.14, p=0.145, \eta_{p}^{2}=0.01\right)$, but did reveal a significant main effect of office type $\left(F(3,267)=6.72, p<0.001, \eta_{p}^{2}=0.07\right)$, with participants generally giving higher well-being ratings in cellular and shared-room offices than in open office types. More importantly and consistent with $\mathrm{H} 1$, this main effect was qualified by the predicted two-way interaction $\left(F(3,267)=6.84, p<0.001, \eta_{p}^{2}=0.07\right)$. To better understand the nature of this interaction, the results were examined for each evaluation domain separately.

For cognitive well-being evaluations, office type had a highly significant impact on participants' ratings $\left(F(3,267)=10.91, p<0.001, \eta_{p}^{2}=0.11\right)$ and a significant linear trend $(F(1,267)=32.04, p<0.001)$. Specifically, participants' ratings related to cognitive evaluations were the highest in cellular offices $(M=2.35, \mathrm{SD}=1.27)$, slightly lower in sharedroom offices $(M=2.21, \mathrm{SD}=1.43)$, lower in small open offices $(M=1.53$, $\mathrm{SD}=1.81)$ and lowest in medium-sized open offices $(M=0.62, \mathrm{SD}=2.02)$; see Table 1 for post hoc tests and Figure 2a for a graphical representation of the results.

However, for affective evaluations, office type did not have a significant impact on participants' ratings $\left(F(3,267)=1.56, p=0.200, \eta_{p}^{2}=0.02\right)$, although there was a linear trend that was marginally below the conventional level of statistical significance $(F(1,267)=4.50$, 
$p=0.035$ ). Fisher's $r$-to- $z$ transformation (cf. Otterbring, 2017) on the effect sizes obtained for the cognitive and affective evaluations revealed that the effect size for the cognitive (vs affective) evaluation domain was significantly larger $(z=2.33, p=0.020)$. Despite the weaker impact of office type on affective evaluations, participants' ratings on the affective evaluations index were yet again highest in cellular offices $(M=1.80$, SD $=1.54)$, slightly lower in shared-room offices ( $M=1.67, \mathrm{SD}=1.48)$, lower in small open offices $(M=1.48$, $\mathrm{SD}=1.53)$ and lowest in medium-sized open offices $(M=1.21, \mathrm{SD}=1.15)$; see Figure $2 \mathrm{~b}$. Presented another way, participants' ratings on the cognitive evaluation domain were significantly higher than their ratings in the affective evaluation domain among those working in cellular offices $\left(F(1,75)=17.56, p<0.001, \eta_{p}^{2}=0.19\right)$ and shared-room offices $\left(F(1,44)=4.77, p=0.034, \eta_{p}^{2}=0.10\right)$. However, among participants working in small open offices, the ratings on these variables did not differ significantly $(F(1,112)=0.12, p=0.733)$. Finally, for participants working in the medium-sized open offices, the order was reversed, meaning that their ratings were significantly higher for the affective evaluation domain compared to the cognitive evaluation domain $\left(F(1,36)=6.61, p=0.014, \eta_{p}^{2}=0.16\right)$, although their ratings were the least positive on both these evaluation domains compared to all other office type groups.

\begin{tabular}{lllr}
\hline & Office type & Comparison & $p$-value \\
\hline Cognitive evaluations & Cellular office & Shared-room office & 0.655 \\
& & Small open office & 0.001 \\
& & Medium-sized open office & $<0.001$ \\
& Shared-room office & Small open office & 0.020 \\
& Sedium-sized open office & $<0.001$ \\
Perceived noise & Cellular office & Medium-sized open office & 0.004 \\
& & Shared-room office & 0.531 \\
& Shared-room office & Medium-sized open office & 0.002 \\
& & Small open office & $<0.001$ \\
& Small open office & Medium-sized open office & 0.001 \\
& & Medium-sized open office & $<0.001$ \\
& & & 0.045 \\
\hline
\end{tabular}

\section{Cognitive Evaluations}

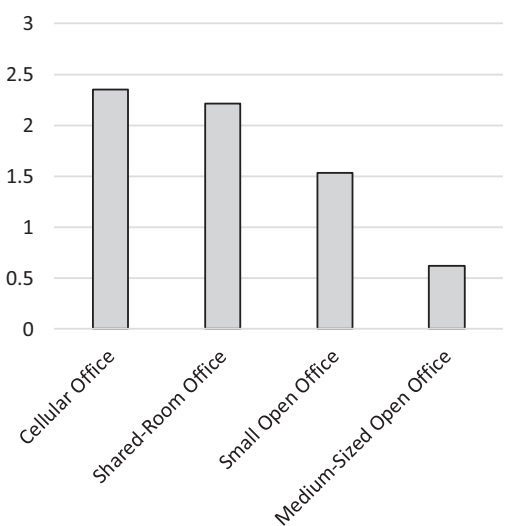

(a)

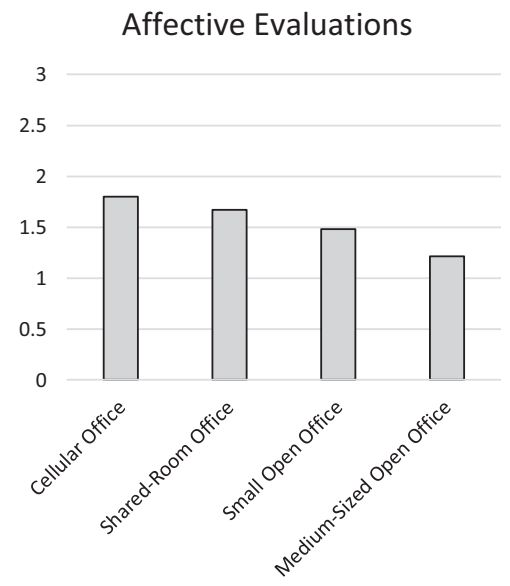

(b)
Office types, noise, and well-being

Table 1.

Post-hoc tests (LSD) examining the differences in cognitive evaluations and perceived noise levels at work between office types
Figure 2. The impact of office types on cognitive and affective evaluations 
JMP

36,4

In sum, these findings demonstrate that well-being-responses were consistently less positive - regardless of evaluation domain - in open offices. However, as the impact of office type on cognitive evaluations was stronger than that of affective evaluations, there was a sharper decrease in cognitive (vs affective) evaluations between cellular and shared-room offices, on the one hand, and open offices, on the other hand, which explains why participants in medium-sized open offices reported more favorable affective than cognitive evaluations, despite that they scored lowest on both evaluation domains compared to participants in all other office types.

\section{Perceived noise mediates the impact of office type on well-being evaluations}

To examine whether perceived noise levels at work mediated the impact that office type had on participants' ratings in the cognitive and affective evaluation domain (H2), a mediation analysis was conducted using the PROCESS computational tool (PROCESS Model 4; Hayes, 2013). Office type was the predictor $(1=$ cellular office, $2=$ shared-room office, $3=$ small open office, 4 = medium-sized open office), perceived noise levels at work acted as the mediator and a difference score (cf. Otterbring et al., 2018b) between cognitive and affective well-being evaluations served as the outcome variable. To create the difference score, the responses related to affective evaluations were subtracted from those related to cognitive evaluations. This analytic choice was adopted because the evaluation domain (cognitive vs affective) was treated as a within-subjects factor in the present study, thereby precluding the possibility to include both cognitive and affective evaluations simultaneously in a regular PROCESS model. Thus, while the tested model corresponds to a simple mediation analysis, it is equivalent to a moderated mediation model, given that the difference score corresponds to the interaction in the mixed ANOVA described above.

Mirroring the above ANOVA results, the total effect of office type on participants' evaluations was significant $(b=-0.34, t=-4.19, p<0.001)$, meaning that their well-being ratings were less positive as the office became relatively more open, especially regarding cognitive (vs affective) evaluations. The effect of office type on noise levels was also significant $(b=-0.40, t=-4.85, p<0.001)$, as was the effect of noise levels on participants' evaluations $(b=0.22, t=3.74, p<0.001)$ [3]. This means that participants perceived noise levels to be less satisfactory in open office spaces relative to cellular and shared-room offices, and that more favorable noise perceptions were linked to more positive cognitive relative to affective evaluations. However, when the evaluative ratings were regressed on both noise levels and office type, the effect of office type was reduced in significance $(b=-0.25, t=-3.06, p=0.003)$. Indeed, a 95\% confidence interval (CI) revealed that the conditional indirect effect through noise levels did not contain zero (95\% CI [-0.158, -0.036]). Thus, participants in open offices reported relatively lower cognitive (vs affective) ratings than participants working in cellular and sharedroom offices because perceived noise levels at work were less satisfactory in such open spaces [4].

Table 2 depicts the zero-order correlations between office types (cellular office, sharedroom office, small open-plan office and medium-sized open-plan office), noise levels and affective as well as cognitive well-being evaluations.

Table 2.

Zero-order correlations between key variables

\begin{tabular}{lcccc}
\hline & Office type & Perceived noise & Affective evaluations & Cognitive evaluations \\
\hline Office type & 1 & $-0.28^{* *}$ & $-0.13^{*}$ & $-0.32^{* *}$ \\
Perceived noise & - & 1 & $0.31^{* *}$ & $0.49^{* *}$ \\
Affective evaluations & - & - & - & $0.61^{* *}$ \\
Cognitive evaluations & - & - & & \\
Note(s): ${ }^{*} p<0.05$ & & & & \\
$* * p<0.001$ & & & & \\
\end{tabular}




\section{Discussion}

The present study aimed to investigate the links between office types (cellular, shared-room, small and medium-sized open-plan) and employees' subjective well-being regarding cognitive and affective evaluations and the role noise levels at work have on the aforementioned associations. Drawing on appraisal theories and other adjacent accounts, a significant difference was found between office types on the well-being dimension related to cognitive, but not affective, evaluations, with employees working in cellular and shared-room offices reporting significantly higher ratings on the cognitive evaluation domain compared to employees working in open-plan offices [5]. Moreover, employees working in medium-sized open-plan offices reported significantly lower cognitive evaluation scores than employees working in all other office types. This pattern of results was mediated by noise levels, with employees in open-plan (vs cellular and shared-room) offices reporting less satisfactory noise levels and, in turn, lower well-being scores, especially regarding the cognitive (vs affective) well-being dimension.

To the best of the authors' knowledge, this study is among the first to compare the relative impact of office types on both cognitive and affective well-being dimensions while simultaneously testing and providing empirical support for the process (i.e. perceived noise) explaining the connection between office types and such well-being-related aspects. Thus, a key contribution of the current work is the finding that employees may evaluate cognitive well-being aspects of their workplace differently as a function of office type, without necessarily having a pronounced impact on their affective well-being evaluations. This indicates that employees may deem their working environment as undesirable from a cognitive point of view, due to disturbing events and corresponding concentration difficulties, while still perceiving that environment as affectively adequate. Prior qualitative research has found indirect support for this notion. Using in-depth interviews with employees working in different office types, Bodin Danielsson (2015) found that although open offices were critically evaluated on functional aspects related to noise levels, employees still valued the communal components and the aesthetic appeal associated with such open office spaces. Taken together, these findings suggest that human-environment interaction in organizational settings is a complex issue. The present study takes a first step to uncover the underlying processes illuminating why certain features of the office environment may determine organizational outcomes, and thus addresses the call for more research in this managerially relevant research area (Ashkanasy et al., 2014), with potential downstream effects on employees' productivity and the financial success of companies (Bernstein and Turnban, 2018).

Increased noise levels have been shown to amplify risks for high blood pressure and cardiovascular morbidity (Davies et al., 2005; Van Kempen et al., 2002; Willich et al., 2006), as well as other motivational and observational signs of elevated stress (Kristiansen et al., 2009). Therefore, the findings reported herein should also have important implications for public health and interior design decisions meant to minimize background noise at the workplace. Relatedly, the present study adds further evidence of the deteriorating effects associated with open-plan offices. Their claimed cost efficiency may be applicable in the short run, but could eventually escalate in a chaotic chain of costly consequences. Indeed, open office layouts and visually unbounded areas have been linked to increased sickness absence (Bodin Danielsson et al., 2014; Pejtersen et al., 2011), decreased ease of communication with colleagues (Bernstein and Turban, 2018; Otterbring et al., 2018a) and cognitive impairments on work tasks requiring a higher need for concentration (Roberts et al., 2019; Seddigh et al., 2014). However, despite such findings and the results obtained in this study, it is important to note that open office types are not always aversive. Research suggests that the "boon or bane" of open offices may be occupation and task specific, such that employees in certain creative areas
Office types, noise, and well-being 
JMP

36,4 (e.g. software engineers) may be more communicative in these office types, with synergy effects on efficiency and productivity (Becker, 2004; Mishra et al., 2012).

Based on the results from this study, companies and organizations that have already implemented the concept of open-plan offices should make a great effort to reduce the perceived noise levels through functional decisions regarding furniture and carpet selection, wall material and other facets of the interior office design. Such interior design decisions are arguably even more important in those occupations where employees' work tasks require higher levels of concentration and cognitive effort. Thus, improved noise perceptions in these occupations may at least partially mitigate the many negative aspects associated with open office spaces. However, considering the fact that rental costs account for less than $10 \%$ of businesses' operating costs, whereas staff costs account for roughly $90 \%$ (Rolfö et al., 2018), decision makers may be well advised to focus less on short-term profitability in relation to the specific choice of office type. In other words, adopting a more future-focused mindset, in which the long-term consequences for workers' health, cognitive abilities and job satisfaction are prioritized over somewhat higher short-term expenses, may be a competitive strategy for companies with long-lasting financial benefits, happier and healthier employees and a more productive workplace. Moreover, emotions have an important role in determining organizational behavior (Ashkanasy et al., 2014; Ashkanasy and Daus, 2002; Chen et al., 2016) and need to be given a more prominent role in organizational science. In addition, affective aspects are also associated with ease of communication with colleagues (Otterbring et al., 2018a), which, in turn, is assumed to be a key driver of productivity, at least in certain occupations (Bernstein and Turban, 2018). Therefore, companies should strive to create a pleasant work environment, characterized by emotional well-being among employees, vibrant face-to-face collaboration and office layouts that enable concentration and facilitate cognitive performance.

\section{Limitations and future research}

The current work has certain limitations. Firstly, the response rate is relatively low and, consequently, potentially problematic. However, this can be explained by the fact that: (1) the survey was only open during four consecutive workdays and (2) no reminders were sent out to the employees during this narrow time window. For these reasons, and given that the primary purpose of the present research was to test theoretically derived hypotheses rather than equating sample means with population values, response rate issues are arguably less severe.

Secondly, real estate agents constitute a special category of office workers. They have particularly good knowledge of the prerequisites of different office types, such as the increased focus on space effectiveness, which potentially could lead to an increased tolerance to work in open-plan offices. At the same time, they are known to be especially exposed to jobrelated stress (Snyder et al., 2011), which should decrease rather than increase their tolerance for environmental stressors such as the higher noise levels characterizing open office spaces. Real estate agents also tend to conduct the majority of their work individually outside the office and typically do not work widely in various project-based activities together with their colleagues. This is different from a set of other occupations, such as software developers, architects and development engineers, where working project-based together with colleagues is a common component of work.

Thirdly, common method bias is a general concern in studies relying on self-report data (Podsakoff et al., 2003). However, this bias source can be meaningfully mitigated by varying the scale properties (e.g. the scale types, scale anchors and the number of scale points) for the measures used to capture different constructs (Cronbach, 1946; Jordan and Troth, 2020; Kothandapani, 1971; Podsakoff et al., 2003). Indeed, Podsakoff et al. (2012) argued that 
"minimizing common scale properties is always a good idea" (p. 551). Therefore, considering that the present study measured the predictor as a continuous variable while capturing the mediator through a seven-point scale (anchored at 1 and 7) and the well-being outcomes through nine-point scales (anchored at -4 and +4 ), the impact of common method bias should have been reduced.

Independent of whether the current study is immune against common method bias, future research would benefit from capturing the impact of different office types on workers' behavioral responses or at least make an effort to go beyond the archetypical approach of solely collecting retrospective self-report data (Cialdini, 2009; Folkman et al., 1986a; Otterbring et al., 2020; Rolschau et al., 2020). Indeed, behavioral studies in this research area are extremely rare, but can reveal profound insights. For instance, Bernstein and Turban (2018) examined the direct behavioral impact of open office spaces on the volume of face-toface and electronic interaction (e.g. emails) among workers in two intervention-based field studies at headquarters transitioning to open office spaces. In contrast to common beliefs, the amount of face-to-face interaction actually decreased by roughly $70 \%$ in both studies, with an associated increase in electronic interaction. These findings lead the authors to conclude that, instead of creating vibrant face-to-face collaboration, open offices seem to trigger employees to socially withdraw from their colleagues and replace such face-to-face interaction with email exchanges (Bernstein and Turban, 2018). However, regardless of how desirable methodological diversity is, it should be noted that the impact of open (vs private) offices have been consistently demonstrated on a set of organizational outcomes in methods ranging from cross-sectional surveys, through field studies, to experimental research (e.g. Bernstein and Turban, 2018; Hoendervanger et al., 2019; Otterbring et al., 2018a). This implies considerable generalizability in findings obtained across study paradigms and settings, but also indicates that self-report data should not automatically be discarded.

Finally, it is likely that factors other than those measured in the present research, such as lighting, aesthetic aspects and air quality, may have influenced the results to some extent (e.g. Robertson et al., 1989; Rolfö et al., 2018). Moreover, although an examination of the multidimensional nature of noise fell beyond the current study purpose, noise still contains several important facets, which were not captured through our global, single-item measure. As such, a fruitful avenue for future research is to disentangle which specific noise dimension that has the strongest impact on employees' affective and cognitive well-being responses as a function of office type. Future research should also be conducted in different settings and on other occupations to investigate the replicability and generalizability of the present findings regarding the differences in cognitive (vs affective) well-being of employees and the mediating mechanism of perceived noise levels across office types and occupations.

\section{Notes}

1. An anonymous reviewer questioned whether one of the cognitive evaluation items (my office is badgood) was an adequate measure of cognitive operations. However, the nature and significance of our results do not change as a function of whether this item is included or excluded from the analyses, indicating robustness of our findings.

2. For transparency, the main results pertaining to this index variable were as follows: office type had a significant impact on participants' ratings $\left(F(3,267)=5.46, p=0.001, \eta_{p}^{2}=0.06\right)$, and a significant linear trend emerged between office type and the negative activation/positive deactivation index $(F(1,267)=16.19, p<0.001)$. Participants working in cellular offices felt least time pressed and stressed $(M=1.59, \mathrm{SD}=1.52)$, followed by participants working in shared-room offices $(M=1.29$, $\mathrm{SD}=1.38)$. Participants working in small open offices $(M=1.01, \mathrm{SD}=1.88)$ and medium-sized open offices ( $M=0.28, \mathrm{SD}=1.58)$ felt more time pressed and stressed. Notably, post-hoc tests (LSD) revealed that participants working in medium-sized open plan offices felt significantly more time pressed and stressed than participants in all other office types ( $p s \leq 0.023)$.

Office types, noise, and well-being 
JMP

36,4

3. Indeed, a one-way ANOVA on perceived noise levels at work found a significant effect of office type $\left(F(3,267)=9.68, p<0.001, \eta_{p}^{2}=0.10\right)$ and a significant linear trend $(F(1,267)=25.03, p<0.001)$. Participants perceived noise levels to be roughly equal in cellular offices $(M=4.37, \mathrm{SD}=1.56)$ and shared-room offices $(M=4.53, \mathrm{SD}=1.47)$, but were less satisfied with noise levels at small open offices $(M=3.72, \mathrm{SD}=1.30)$ and least satisfied at medium-sized open offices $(M=3.18, \mathrm{SD}=1.24)$; see Table 1 for post-hoc tests. Interestingly, one-sampled $t$-tests further revealed that participants working in cellular offices $(t(75)=2.06, p=0.043)$ and shared-room offices $(t(44)=2.43, p=0.019)$ perceived noise levels to be significantly more positive compared to the scale midpoint of 4 . By contrast, participants working in small open offices $(t(112)=-2.33, p=0.022)$ and medium-sized open offices $(t(36)=-4.03, p<0.001)$ perceived noise levels to be significantly more negative compared to the scale midpoint.

4. An anonymous reviewer raised concerns about our analytic approach pertaining to the use of a difference score (John, 1981; Page Jr and Spreng, 2012; for some opposing views, see Allison, 1990; Gollwitzer et al., 2014; Thomas and Zumbo, 2012) and our treatment of cognitive and affective evaluations as representing a within-subjects factor. As an alternative way of demonstrating the discussed spillover effect, whereby open-plan offices and their associated increased noise levels may not only have a negative impact on participants' cognitive evaluations, but also on their affective evaluations, we therefore conducted a serial mediation model (PROCESS Model 6; Hayes, 2013). Office type served as the predictor, perceived noise levels at work acted as the first mediator, cognitive evaluations constituted the second mediator and affective evaluations served as our outcome variable. This analysis revealed that perceived noise levels at work did not alone exert a significant conditional indirect effect for the association between office type and affective evaluations $(95 \% \mathrm{CI}=[-0.057,0.041])$. However, the office type-affective evaluations link was indirect through participants' cognitive evaluations (95\% $\mathrm{CI}=[-0.270,-0.077]$. Importantly, the link between office type and affective evaluations was indirect through perceived noise levels at work and cognitive evaluations $(95 \% \mathrm{CI}=[-0.170,-0.061]$ ), indicating serial mediation. Note that this analysis is consistent with a cognitive appraisal conceptualization (e.g. Folkman et al., 1986a, b; Lazarus, 1991), given that cognitive evaluations are analyzed as antecedents of affective evaluations. However, this chain of events - with cognitive operations preceding affective judgments - cannot be taken for granted according to a dual-process account (e.g. Kahneman, 2011; Metcalfe and Mischel, 1999; Petty and Cacioppo, 1986; Strack and Deutsch, 2004; Zajonc, 1980), which explains the alternative analytic approach used in our main analyses.

5. Note, however, that there was still a negative linear trend $(\phi=0.035)$ between office type and affective evaluations in the same direction as that of cognitive evaluations, but significantly less pronounced, consistent with $\mathrm{H} 1$. As requested by an anonymous reviewer, and despite the nonsignificant omnibus test of the ANOVA pertaining to affective evaluations, follow-up post-hoc tests (LSD) only revealed a significant difference in affective evaluations between employees working in cellular vs medium-sized open-plan offices ( $\phi=0.047$; for means and standard deviations, see the Results section). All other comparisons were non-significant ( $p s \geq 0.146$ ).

\section{References}

Abdel-Khalek, A.M. (2006), "Measuring happiness with a single-item scale", Social Behavior and Personality: An International Journal, Vol. 34 No. 2, pp. 139-150.

Allison, P.D. (1990), "Change scores as dependent variables in regression analysis", Sociological Methodology, Vol. 20, pp. 93-114.

Alvesson, M. and Sandberg, J. (2011), "Generating research questions through problematization", Academy of Management Review, Vol. 36 No. 2, pp. 247-271.

Ashkanasy, N.M. (2011), "Advancing theory: more than just 'gap filling”, Journal of Organizational Behavior, Vol. 32 No. 6, pp. 819-821.

Ashkanasy, N.M. and Daus, C.S. (2002), "Emotion in the workplace: the new challenge for managers", Academy of Management Perspectives, Vol. 16 No. 1, pp. 76-86. 
Ashkanasy, N.M., Ayoko, O.B. and Jehn, K.A. (2014), "Understanding the physical environment of work and employee behavior: an affective events perspective", Journal of Organizational Behavior, Vol. 35 No. 8, pp. 1169-1184.

Bakker, A.B. and Oerlemans, W. (2011), "Subjective well-being in organizations", The Oxford Handbook of Positive Organizational Scholarship, Vol. 49, pp. 178-189.

Becker, F. (1981), Workspace: Creating Environments in Organizations, Praeger, New York.

Becker, F. (2004), Office at Work: Uncommon Workspace Strategies that Add Value and Improve Performance, John Wiley \& Sons, San Francisco, CA.

Office types, noise, and well-being

Bell, P.A., Greene, T.E., Fischer, J.D. and Baum, A. (Eds) (2001), Environmental Psychology, 5th ed., Harcourt College Publisher, Orlando, FL.

Bergkvist, L. and Rossiter, J.R. (2007), "The predictive validity of multiple-item versus single-item measures of the same constructs", Journal of Marketing Research, Vol. 44 No. 2, pp. 175-184.

Bernstein, E.S. and Turban, S. (2018), "The impact of the 'open' workspace on human collaboration", Philosophical Transactions of the Royal Society B: Biological Sciences, Vol. 373 No. 1753, p. 20170239.

Birkinshaw, J., Healey, M.P., Suddaby, R. and Weber, K. (2014), "Debating the future of management research", Journal of Management Studies, Vol. 51 No. 1, pp. 38-55.

Block, L.K. and Stokes, G.S. (1989), "Performance and satisfaction in private versus nonprivate work settings", Environment and Behavior, Vol. 21 No. 3, pp. 277-297.

Bodin Danielsson, C. (2015), “Aesthetics versus function in office architecture: employees' perception of the workplace", Nordic Journal of Architectural Research, Vol. 2, pp. 11-40.

Bodin Danielsson, C. and Bodin, L. (2008), "Office-type in relation to health, well-being and job satisfaction among employees", Environment and Behavior, Vol. 40 No. 5, pp. 636-668.

Bodin Danielsson, C. and Bodin, L. (2009), "Differences in satisfaction with office environment among employees in different office types", Journal of Architectural and Planning Research, Vol. 26 No. 3, pp. 2241-2257.

Bodin Danielsson, C., Chungkham, H.S., Wulff, C. and Westerlund, H. (2014), "Office design's impact on sick leave rates", Ergonomics, Vol. 57 No. 2, pp. 139-147.

Bodin Danielsson, C., Bodin, L., Wulff, C. and Theorell, T. (2015), "The relation between office type and workplace conflict: a gender and noise perspective", Journal of Environmental Psychology, Vol. 42, pp. 161-171.

Brockman, R., Ciarrochi, J., Parker, P. and Kashdan, T. (2017), "Emotion regulation strategies in daily life: mindfulness, cognitive reappraisal and emotion suppression", Cognitive Behaviour Therapy, Vol. 46 No. 2, pp. 91-113.

Carlopio, J.R. and Gardner, D. (1992), "Direct and interactive effectsd of the physical work environment on attitudes", Environment and Behavior, Vol. 24 No. 5, pp. 579-601.

Chen, Y., Wen, Z., Peng, J. and Liu, X. (2016), "Leader-follower congruence in loneliness, LMX and turnover intention”, Journal of Managerial Psychology, Vol. 31 No. 4, pp. 864-879.

Cialdini, R.B. (2009), "We have to break up”, Perspectives on Psychological Science, Vol. 4 No. 1, pp. 5-6.

Clark, L.A. and Watson, D. (1995), "Constructing validity: basic issues in objective scale development", Psychological Assessment, Vol. 7 No. 3, pp. 309-319.

Cronbach, L.J. (1946), "Response sets and test validity", Educational and Psychological Measurement, Vol. 6 No. 4, pp. 475-494.

Davies, H.W., Teschk, K., Kennedy, S.M., Hodgson, M.R., Hertzman, C. and Demers, P.A. (2005), "Occupational exposure to noise and mortality from acute myocardial infarction", Epidemiology, Vol. 16, pp. 25-32.

Ettema, D., Gärling, T., Eriksson, L., Friman, M., Olsson, L.E. and Fujii, S. (2011), "Satisfaction with travel and subjective well-being: development and test of a measurement tool", Transportation Research Part F: Traffic Psychology and Behaviour, Vol. 14 No. 3, pp. 167-175. 
Evans, G. and Johnson, D. (2000), "Stress and open-office noise", Journal of Applied Psychology, Vol. 85 No. 5, pp. 779-783.

Folkman, S., Lazarus, R.S., Dunkel-Schetter, C., DeLongis, A. and Gruen, R.J. (1986a), "Dynamics of a stressful encounter: cognitive appraisal, coping, and encounter outcomes", Journal of Personality and Social Psychology, Vol. 50 No. 5, pp. 992-1003.

Folkman, S., Lazarus, R.S., Gruen, R.J. and DeLongis, A. (1986b), "Appraisal, coping, health status, and psychological symptoms", Journal of Personality and Social Psychology, Vol. 50 No. 3, pp. 571-579.

Frijda, N.H. (1987), "Emotion, cognitive structure, and action tendency", Cognition and Emotion, Vol. 1 No. 2, pp. 115-143.

Frijda, N.H. (1988), “The laws of emotion”, American Psychologist, Vol. 43 No. 5, pp. 349-358.

Friman, M., Rosenbaum, M.S. and Otterbring, T. (2020), "The relationship between exchanged resources and loyalty intentions", The Service Industries Journal, Vol. 40 Nos 11-12, pp. 846-865.

Gardner, D.G., Cummings, L.L., Dunham, R.B. and Pierce, J.L. (1998), "Single-item versus multiple-item measurement scales: an empirical comparison", Educational and Psychological Measurement, Vol. 58 No. 6, pp. 898-915.

Goldman, A. (1994), "A briefing on cultural and communicative sources of Western-Japanese interorganizational conflict”, Journal of Managerial Psychology, Vol. 9 No. 1, pp. 7-12.

Gollwitzer, M., Christ, O. and Lemmer, G. (2014), "Individual differences make a difference: on the use and the psychometric properties of difference scores in social psychology", European Journal of Social Psychology, Vol. 44 No. 7, pp. 673-682.

Gross, J.J. and John, O.P. (2003), "Individual differences in two emotion regulation processes: implications for affect, relationships, and well-being", Journal of Personality and Social Psychology, Vol. 85 No. 2, pp. 348-362.

Hambrick, D.C. (2007), “The field of management's devotion to theory: too much of a good thing?", Academy of Management Journal, Vol. 50 No. 6, pp. 1346-1352.

Hayes, A.F. (2013), Introduction to Mediation, Moderation, and Conditional Process Analysis: A Regression-Based Approach, Guilford Press, New York.

Hoendervanger, J.G., Van Yperen, N.W., Mobach, M.P. and Albers, C.J. (2019), "Perceived fit in activitybased work environments and its impact on satisfaction and performance", Journal of Environmental Psychology, Vol. 65, p. 101339.

Hofmann, W., Friese, M. and Strack, F. (2009), "Impulse and self-control from a dual-systems perspective”, Perspectives on Psychological Science, Vol. 4 No. 2, pp. 162-176.

Jahncke, H., Hygge, S., Halin, N., Green, A.M. and Dimberg, K. (2011), "Open-plan office noise: cognitive performance and restoration”, Journal of Environmental Psychology, Vol. 31, pp. 373-382.

Johns, G. (1981), "Difference score measures of organizational behavior variables: a critique", Organizational Behavior and Human Performance, Vol. 27 No. 3, pp. 443-463.

Jordan, P.J. and Troth, A.C. (2020), "Common method bias in applied settings: the dilemma of researching in organizations", Australian Journal of Management, Vol. 45 No. 1, pp. 3-14.

Kaarlela-Tuomaala, A., Helenius, R., Keskinen, E. and Hongisto, V. (2009), "Effects of acoustic environment on work in private office rooms and open-plan offices-longitudinal study during relocation”, Ergonomics, Vol. 52 No. 11, pp. 1423-1444.

Kahneman, D. (2011), Thinking: Fast and Slow, Macmillan, New York, NY.

Keus van de Poll, M. and Sörqvist, P. (2016), "Effects of task interruption and background speech on word processed writing", Applied Cognitive Psychology, Vol. 30 No. 3, pp. 430-439.

Kothandapani, V. (1971), "Validation of feeling, belief, and intention to act as three components of attitude and their contribution to prediction of contraceptive behavior", Journal of Personality and Social Psychology, Vol. 19 No. 3, pp. 321-333. 
Kristiansen, J., Mathiesen, L., Nielsen, P.K., Hansen, Å.M., Shibuya, H., Petersen, H.M., Lund, S.P., Skotte, J., Jørgensen, M.B. and Søgaard, K. (2009), "Stress reactions to cognitively demanding tasks and open-plan office noise", International Archives of Occupational and Environmental Health, Vol. 82 No. 5, pp. 631-641.

Lazarus, R.S. (1991), “Cognition and motivation in emotion”, American Psychologist, Vol. 46 No. 4, pp. 352-367.

Lerner, J.S., Li, Y., Valdesolo, P. and Kassam, K.S. (2015), "Emotion and decision making”, Annual Review of Psychology, Vol. 66, pp. 799-823.

Ma, L. and Ye, R. (2019), "Does daily commuting behavior matter to employee productivity?", Journal of Transport Geography, Vol. 76, pp. 130-141.

Metcalfe, J. and Mischel, W. (1999), "A hot/cool-system analysis of delay of gratification: dynamics of willpower", Psychological Review, Vol. 106 No. 1, pp. 3-19.

Mishra, D., Mishra, A. and Ostrovska, S. (2012), "Impact of physical ambiance on communication, collaboration and coordination in agile software development: an empirical evaluation", Information and Software Technology, Vol. 54 No. 10, pp. 1067-1078.

Nagy, M.S. (2002), "Using a single-item approach to measure facet job satisfaction", Journal of Occupational and Organizational Psychology, Vol. 75 No. 1, pp. 77-86.

Nemecek, J. and Grandjean, E. (1973), "Results of an ergonomic investigation of large-space offices", Human Factors, Vol. 15 No. 2, pp. 111-124.

Nunnally, J.C. (1978), Psychometric Theory, 2nd ed., McGraw-Hill, New York.

Oldham, G.R. and Brass, D.J. (1979), "Employee reactions to an open-plan office: a naturally occurring quasi-experiment”, Administrative Science Quarterly, Vol. 24 No. 2, pp. 267-284.

Otterbring, T. (2017), "Smile for a while: the effect of employee-displayed smiling on customer affect and satisfaction", Journal of Service Management, Vol. 28 No. 2, pp. 284-304.

Otterbring, T. (2020), "Appetite for destruction: counterintuitive effects of attractive faces on people's food choices", Psychology and Marketing, Vol. 37 No. 11, pp. 1451-1464.

Otterbring, T., Pareigis, J., Wästlund, E., Makrygiannis, A. and Lindström, A. (2018a), "The relationship between office type and job satisfaction: testing a multiple mediation model through ease of interaction and well-being", Scandinavian Journal of Work, Environment and Health, Vol. 44 No. 3, pp. 330-334.

Otterbring, T., Ringler, C., Sirianni, N.J. and Gustafsson, A. (2018b), "The Abercrombie \& Fitch effect: the impact of physical dominance on male customers' status-signaling consumption", Journal of Marketing Research, Vol. 55 No. 1, pp. 69-79.

Otterbring, T., Sundie, J., Li, Y.J. and Hill, S. (2020), "Evolutionary psychological consumer research: bold, bright, but better with behavior", Journal of Business Research, Vol. 120 November, pp. 473-484.

Page, T.J.Jr. and Spreng, R.A. (2002), "Difference scores versus direct effects in service quality measurement", Journal of Service Research, Vol. 4 No. 3, pp. 184-192.

Pejtersen, J.H., Feveile, H., Christensen, K.B. and Burr, H. (2011), "Sickness absence associated with shared and open-plan offices - a national cross sectional questionnaire survey", Scandinavian Journal of Work, Environment and Health, Vol. 37 No. 5, pp. 376-382.

Petty, R.E. and Cacioppo, J.T. (1986), "The elaboration likelihood model of persuasion", in Communication and Persuasion, Springer, New York, NY, pp. 1-24.

Podsakoff, P.M., MacKenzie, S.B., Lee, J.Y. and Podsakoff, N.P. (2003), "Common method biases in behavioral research: a critical review of the literature and recommended remedies", Journal of Applied Psychology, Vol. 88 No. 5, pp. 879-903.

Podsakoff, P.M., MacKenzie, S.B. and Podsakoff, N.P. (2012), "Sources of method bias in social science research and recommendations on how to control it", Annual Review of Psychology, Vol. 63, pp. 539-569.

Office types, noise, and well-being

(1)

(1)


JMP

36,4

Roberts, A.C., Yap, H.S., Kwok, K.W., Car, J., Soh, C.K. and Christopoulos, G.I. (2019), "The cubicle deconstructed: simple visual enclosure improves perseverance", Journal of Environmental Psychology, Vol. 63, pp. 60-73.

Robertson, A.S., McInnes, M., Glass, D., Dalton, G. and Burge, P.S. (1989), "Building sickness, are symptoms related to the office lighting?", The Annals of Occupational Hygiene, Vol. 33 No. 1, pp. 47-59.

Rolfö, L., Eklund, J. and Jahncke, H. (2018), "Perceptions of performance and satisfaction after relocation to an activity-based office", Ergonomics, Vol. 61 No. 5, pp. 644-657.

Rolschau, K., Wang, Q.J. and Otterbring, T. (2020), "Seeing sweet and choosing sour: compensatory effects of typeface on consumers' choice behavior", Food Quality and Preference, Vol. 85, 103964.

Rynes, S.L., Bartunek, J.M. and Daft, R.L. (2001), “Across the great divide: knowledge creation and transfer between practitioners and academics", Academy of Management Journal, Vol. 44 No. 2, pp. 340-355.

Seddigh, A., Berntson, E., Danielson, C.B. and Westerlund, H. (2014), "Concentration requirements modify the effect of office type on indicators of health and performance", Journal of Environmental Psychology, Vol. 38, pp. 167-174.

Smith-Jackson, T.L. and Klein, K.W. (2009), "Open-plan offices: task performance and mental workload", Journal of Environmental Psychology, Vol. 29 No. 2, pp. 279-289.

Snyder, J.L., Claffey Sr, G.F. and Cistulli, M.D. (2011), "How similar are real estate agents and humanservice workers? A study of real estate agents' responses to distressed clients", Journal of Business Communication, Vol. 48 No. 3, pp. 300-318.

Strack, F. and Deutsch, R. (2004), "Reflective and impulsive determinants of social behavior", Personality and Social Psychology Review, Vol. 8 No. 3, pp. 220-247.

Suddaby, R. (2014), "Editor's comments: why theory?", The Academy of Management Review, Vol. 39 No. 4, pp. 407-411.

Sundstrom, E. (1986), Work Places: The Psychology of the Physical Environment in Offices and Factories, Cambridge University Press, New York.

Sundstrom, E., Burt, R.E. and Kamp, D. (1980), "Privacy at work: architectural correlates of job satisfaction and job performance", Academy of Management Journal, Vol. 23 No. 1, pp. 101-117.

Sundstrom, E., Town, J.P., Rice, R.W., Osborn, D. and Brill, M. (1994), "Office noise, satisfaction, and performance", Environment and Behavior, Vol. 26 No. 2, pp. 195-222.

Thomas, D.R. and Zumbo, B.D. (2012), "Difference scores from the point of view of reliability and repeated-measures ANOVA: in defense of difference scores for data analysis", Educational and Psychological Measurement, Vol. 72 No. 1, pp. 37-43.

Ursin, H. and Eriksen, H.R. (2004), "The cognitive activation theory of stress", Psychoneuroendocrinology, Vol. 29 No. 5, pp. 567-592.

Van Kempen, E.E., Kruize, H., Boshuizen, H.C., Ameling, C.B., Staatsen, B.A. and de Hollander, A.E. (2002), "The association between noise exposure and blood pressure and ischemic heart disease: a meta-analysis", Environmental Health Perspectives, Vol. 110 No. 3, pp. 307-317.

Wanous, J.P., Reichers, A.E. and Hudy, M.J. (1997), "Overall job satisfaction: how good are single-item measures?”, Journal of Applied Psychology, Vol. 82 No. 2, pp. 247-252.

Westman, J., Olsson, L.E., Gärling, T. and Friman, M. (2017), “Children's travel to school: satisfaction, current mood, and cognitive performance", Transportation, Vol. 44 No. 6, pp. 1365-1382.

Willich, S.N., Wegscheider, K., Stallman, M. and Keil, T. (2006), "Noise burden and the risk of myocardial infarction”, European Heart Journal, Vol. 27, pp. 276-282.

Zajonc, R.B. (1980), "Feeling and thinking: preferences need no inferences", American Psychologist, Vol. 35 No. 2, pp. 151-175. 


\begin{abstract}
About the authors
Tobias Otterbring, PhD Psychology, is a Professor of Marketing at the University of Agder. His research focuses on how the real, imagined or implied presence of other individuals influences people's cognitions, emotions and behavioral responses. Otterbring has published his work in a variety of international academic journals, ranging from psychology, marketing and sustainability to food science, public health and organizational behavior. His work has been featured in Harvard Business Review, Journal of Marketing Research and Psychology and Marketing, as well as in media outlets such as Forbes, New York Times and BBC News. Tobias Otterbring is the corresponding author and can be contacted at: tobias.otterbring@uia.no

Architect Christina Bodin Danielsson is an Associate Professor in Architecture (HumanEnvironment Interaction) at the School of Architecture, KTH, specialized in office design. She is a Practicing Architect working part time in implementing research in design projects at Brunnberg \& Forshed Architects and part time as a researcher. Her field of expertise is inter-disciplinary. Thus, although based in architecture, it involves areas such as occupational health, organizational behavior, stress medicine, social psychology, etc. Bodin Danielsson has completed post-doctoral research at the Stress Research Institute, Stockholm University, and at the Department of Design Analysis (DEA), Cornell University.

Jörg Pareigis is an Assistant Professor in Business Administration and researcher at CTF, Service Research Center at Karlstad University. His research interests evolve around service management, consumer behavior and customer experience. More specifically, he focuses on co-creative aspects in services and is particularly interested in the role of the physical service environment in these situations. He has published his research in international outlets such as the Scandinavian Journal of Work, Environment and Health, Journal of Service Management, Journal of Retailing and Consumer Services, Journal of Decision Systems and Measuring Business Excellence.
\end{abstract}

For instructions on how to order reprints of this article, please visit our website:

www.emeraldgrouppublishing.com/licensing/reprints.htm

Or contact us for further details: permissions@emeraldinsight.com 